\title{
Vocational Rehabilitation of People with Mental Disabilities by Repeated Training of Horticultural Activities
}

\author{
Ga Ae Seol ${ }^{1}$, Suk Young Yun ${ }^{2 *}$, Byung Jin $\mathrm{Choi}^{2}$, Eun Jin Jang ${ }^{2}$, and Hyun Hee Jang ${ }^{3}$ \\ ${ }^{1}$ Doctoral Program in Horticulture, Daegu Catholic University, Gyeongsan 38430, Korea \\ ${ }^{2}$ Professor, Department of Horticulture, Daegu Catholic University, Gyeongsan 38430, Korea \\ ${ }^{3}$ CEO, Sein Flower, 76-20 Okgyenam-ro, Gumi 39190, Korea
}

\section{ABSTRACT}

The purpose of this study was to develop an effective horticultural activity program for the vocational rehabilitation of people with mental disabilities. The subjects of this study were seven persons with mental disabilities in the vocational rehabilitation team of a public health center located in $\mathrm{G}$ city, Gyeongsangbuk-do. A total of 10 horticultural programs were held from October 10 to December 11, 2018. Five programs were selected among those that were easy for the persons with mental illness to handle and their preference was high. In each session, the same task was repeated 10 times and finally changes in hand functions and working speed were measured. As a result, the assembly task of the Purdue Pegboard test was $23.6(\mathrm{SD}=10.5)$ before the program, $26.6(\mathrm{SD}=11.5)$ after planting, $27.7(\mathrm{SD}=12.2)$ after wrapping pots, and 28.0 (SD = 13.9) after making mini flower baskets, $26.9(\mathrm{SD}=12.0)$ after wrapping a single flower, and $29.1(\mathrm{SD}=11.9)$ after making corsages. There was a significant difference between the five programs $(p=.016)$. As a result of measuring the time taken to produce the same 10 products, the average planting time was $9.9(\mathrm{SD}=4.0)$ minutes in the first class and $6.0(\mathrm{SD}=2.3)$ minutes in the second class $(p=.018)$, and making mini flower baskets was reduced from $35.2(\mathrm{SD}=10.1)$ minutes to $21.0(\mathrm{SD}=7.7)$ minutes $(p=.018)$, wrapping a single flower from $23.3(\mathrm{SD}=7.9)$ minutes to $16.2(\mathrm{SD}=7.3)$ minutes $(p=.043)$, and making corsages from $53.6(\mathrm{SD}=15.9)$ to 40.8 (SD = 16.8) minutes $(p=.043)$. The working time was significantly shortened in the second class compared to the first class. The class for wrapping pots was shortened from $52.7(\mathrm{SD}=11.7)$ to $49.6(\mathrm{SD}=17.8)$ minutes, but there was no significant difference $(p=.398)$.

Keywords: dexterity, hand function, working speed

\section{Introduction}

Jobs give humans the meaning of life, and also mental, economic, religious and social meanings. There are differences between individuals depending on the meaning that they place more value on among them, but the act of realizing the meaning through their job itself is the right and responsibility that are equally given to every human being (Jeuong et al., 2019). As humans display their talent and ability through their job and experience self-realization, they can complete the true life of humans. In addition, as the importance of welfare states has been highlighted, those with disabilities who had been viewed as a recipient of benefits as a disadvantaged group started to be able to engage themselves in society as a member regardless of the existence or seriousness of disabilities (Korea Employment Agency for Persons with Disabilities, 1995).

According to the report of the Korea Employment Agency for Persons with Disabilities, the number of registered persons with disabilities in Korea increased from 958,000 in late December, 2000 to 2,545,000 in late December, 2017, up by approximately $165.7 \%$, and the number has been on the rise. The level of economic activities of people with disabilities, however, is still low. The rate of the econom-

Received: October 16, 2019, Revised: November 24, 2019, Accepted: December 16, 2019

First author: Ga Ae Seol, sko475@hanmail.net, (1) https://orcid.org/0000-0002-3612-705X

*Corresponding author. Suk Young Yun, yune1004@cu.ac.kr, (BD https://orcid.org/0000-0002-5862-0021 
ically active and employed population of people with disabilities as of May, 2018 was $37.0 \%$ and $34.5 \%$ respectively, which is only half those of the total population (63.9\% and $61.3 \%$ respectively), but the unemployment rate of people with disabilities was $6.6 \%$, higher than that of the total population $(4.0 \%)$. The rate of the economically active population of people with disabilities was analyzed by the type of disabilities, and the employment rate of people with mental illness was $12.3 \%$ as of May, 2018, much lower than that of the total disabled population (34.5\%). As the disabled population increases, the demand for related policies has been also diversified, and these changes have led to the expansion of targets of those policies and the growing necessity of more individualized and professional policy services (Korea Employment Agency for Persons with Disabilities, 2018). As the Mental Health Act was enacted in Korea in 1995, the direction of policies for the mental health of the mentally challenged shifted from focusing on isolation, accommodation, and long-term hospitalization to deinstitutionalization and community-centered mental health activities, which raised the importance of vocational rehabilitation for people with mental illness (Lee et al., 2014).

The ultimate goal of vocational rehabilitation for people with mental illness is to ensure they can experience self-realization, acquire economic rewards, enjoy opportunities to participate in social activities and lead an independent life by helping them maximize their physical, mental and social functions and find a suitable career for themselves (Mun, 2011). Vocational rehabilitation is known to play an important role in helping people with mental illness raise a sense of economic and social independence and adapt themselves to a local community as a member of the community and to reduce the psychiatric symptoms of people with mental illness who engage in active jobs. However, it has been already difficult for them to find a job due to social prejudices, and even if they overcome them and find a job, it will be also difficult to keep the job. Therefore, an important task in vocational rehabilitation is not only to find a job, but also to keep the job and moreover to happily keep the job (Choi, 2015). Recently, many studies have been conducted to apply horticultural activities to vocational rehabilitation. Kim et al. (2005) provided a horticultural therapy program for high school seniors of a special-education school and reported that the program was very effective in improving motor abilities required for the vocational rehabilitation of those with intellectual disabilities such as agility, and their adaptive behaviors. Lee and Oh (2012) also reported that the process of making topiaries improved the vocational skills and social nature of those with intellectual disabilities and reduced their anti-social behaviors. In addition, Park et al. (2010) provided a horticultural therapy program for people with intellectual disabilities and reported that more changes in their fine motor skills were observed as more sessions were held, which seemed to positively affect the vocational rehabilitation service. $\mathrm{Na}$ (2011) analyzed trends in earlier studies on vocational rehabilitation on the academic journals that were published by the Korea Society of Vocational Rehabilitation from 1991 to June, 2010, and reported that the number of studies related to employment such as job development and placement was the highest (23.6\%), followed by those on the process of vocational rehabilitation $(6.5 \%)$, and those on work adjustment (4.4\%). As the results show, earlier studies relatively less focus on programs for applying it to workplaces and on-the-job training.

Companies that employ more than five workers with disabilities chose as the most serious difficulty in employing persons with disabilities 'difficult to find those with work abilities (17.7\%)' and 'difficult to find jobs suitable for people with disabilities or lacking such jobs (15.7\%; Korea Employment Agency for Persons with Disabilities, 2018). The Act on Welfare of Persons with Disabilities states that a work adjustment and training facility shall establish a plan for individual services for improving the vocational function of those with disabilities who receive training, support the transition of the trainees and provide education and training, focusing on basic training for rehabilitation functions and functional training for occupational core competency. However, there is no specific guideline for them and such facilities in reality face several difficulties such as a high responsibility to pay wages for labor, a low productivity and competitiveness and small business structures, which is known to increase the ratio of time and efforts required for production compared to those required for training. Therefore, it is necessary to suggest clear and 
detailed scopes and content of programs to ensure work adjustment and training facilities perform their original functions (Jeuong et al., 2019).

Against this backdrop, this study aimed to analyze the effects of repetitive movements of horticultural activities on hand functions and working speed and to identify training methods for vocational rehabilitation in detail for improving the ability of people with mental disabilities to work.

\section{Research Methods}

\section{Subjects}

This study was conducted on a total of seven members with mental disabilities of the vocational rehabilitation team of a public health center located in G city, Gyeongsangbuk-do with the consent of the subjects and the head of the mental health welfare center. The subjects were selected among those who had symptoms including schizophrenia (a mental disorder that affects how a person thinks, feels, perceives and behaves, causing a wide range of clinical abnormal symptoms in the character of a person), bipolar disorder (a mental disorder characterized by wide mood swings from manic to depressed), or depression (an illness that affects and lowers the overall mental functions of sufferers everyday or throughout the day such as the content and process of thinking, motives, desires, attention, behaviors, sleep and physical activities). Their average age was 39.9 $(\mathrm{SD}=9.5)$, and they were composed of five males and two females.

\section{Tools}

\section{Program design}

This study selected five programs of making horticultural products among those that Seol et al. (2019) reported had positive effects on the hand functions of those with mental disabilities and their ability to perform horticultural activities after gradually applying them to a vocational rehabilitation class for people with mental illness. Those that were found to be difficult to handle and manage in the process of conducting the study were excluded in this study. The selected programs were composed of planting, wrapping pots, making mini flower baskets, wrapping a single flower and making corsages, and they were performed as follows (Table 1): planting in the Session 1 and 2; wrapping pots in the Session 3 and 4; making mini flower baskets in the Session 5 and 6; wrapping a single flower in the Session 7 and 8; and making corsages in the Session 9 and 10.

\section{Program execution}

This study provided a total of 10 sessions from October 10 to December 11, 2018, and a preliminary test was performed before performing horticultural activities on October 10. The first session was operated on October 12

Table 1. Horticultural activity program and materials used in each program

\begin{tabular}{|c|c|c|c|}
\hline \multirow{2}{*}{ Session } & \multirow{2}{*}{ Program } & \multicolumn{2}{|r|}{ Materials } \\
\hline & & Plant & Non-plant \\
\hline 1 & \multirow{2}{*}{ Planting } & \multirow{2}{*}{ Dracaena sanderiana } & \multirow{2}{*}{ Plastic cups, water beads } \\
\hline 2 & & & \\
\hline 3 & \multirow{2}{*}{ Wrapping pots } & \multirow{2}{*}{ Chrysanthemum morifolium } & \multirow{2}{*}{ OPP film, craft paper, tape, scissors, jute rope } \\
\hline 4 & & & \\
\hline 5 & \multirow{2}{*}{ Making mini flower baskets } & \multirow{2}{*}{ Chrysanthemum morifolium } & \multirow{2}{*}{ Floral foam, baskets } \\
\hline 6 & & & \\
\hline 7 & \multirow{2}{*}{ Wrapping a single flower } & \multirow{2}{*}{ Rosa hybrida } & \multirow{2}{*}{ OPP film, tape, wrapping paper } \\
\hline 8 & & & \\
\hline 9 & \multirow{2}{*}{ Making corsages } & \multirow{2}{*}{ Dianthus caryophyllus } & \multirow{2}{*}{ Floral tape, leaves, ribbons, clothing pins } \\
\hline 10 & & & \\
\hline
\end{tabular}


(Friday), and a session was operated for 2 hours every Tuesday since then from October 16 to December 11. In each session, one horticultural product was produced ten times in a repetitive way. The same activity that was used in the previous session was repeated one more time in the next session. As 10 pieces of each of five horticultural products were produced during two sessions, the same activity was repeated a total of 20 times. Changes in the hand functions and working speed of subjects were measured.

The sessions were led by one Grade I welfare horticultural therapist certified by the Korean Horticultural Therapy Association, and were assisted by one Grade II welfare horticultural therapist and two trainees.

\section{Assessment tools}

(1) Manual dexterity (Purdue Pegboard Test)

The Purdue Pegboard is a tool developed by Joseph Tiffin, an industrial psychologist at Purdue University, to select workers in industrial settings by testing manual dexterity such as the gross movements of fingers, hands and arms and the fine motor functions of fingertips. The Purdue Pegboard is a test tool recognized by those who assess the ability to work and has been widely used to test the work ability of counselees in many vocational rehabilitation facilities for people with disabilities (Kang, 2004). This study used the revised version of the tool (Model 32020) developed by Lafayette Instrument Company that is used by the Korea Employment Agency for Persons with Disabilities for vocational assessment. The tester first demonstrated how to use the tool, and subjects used the tool after fully understanding the tool through practices. The dominant hand of subjects was tested first, and their non-dominant hand was tested later. After that, their both hands were tested and assembly was tested as well. Each test was repeated three times. The time limit for each test for dominant hand, non-dominant hand and both hands was 30 seconds and that for assembly was 60 seconds. Each test began and ended with the signal "Start" and "Stop" respectively and when subjects dropped the tool, they were instructed to leave it as it was and continue to complete the test (Kim, 2012). After sessions were completed, the assistant instructor and subject sat face-to-face to perform the test following the assessment standards mentioned above. Since it takes long hours to conduct each test one-on-one on individual subjects after each session, the test was performed after two sessions were completed.

(2) Working speed measurement and individual observation

One type of horticultural product was produced in two sessions, and 10 pieces of the same product were made in each session by repeating the same program 10 times. The time spent to produce 10 pieces in each session was measured and changes in the working speed of subjects after completing two sessions were observed. Each subject's process of producing each product and outcomes were compared. In every session, the assistant instructor measured the time spent to produce them using a timer during the program and noted down any unusual things or differences observed during the process of production or outcomes.

\section{Data analysis}

The collected data were statistically processed and analyzed using the SPSS WIN 18.0 program. Differences in hand functions between programs were analyzed using the Friedman test and changes in the working speed of subjects were analyzed using the Wilcoxon signed-rank test.

\section{Results and Discussion}

\section{Changes in hand functions}

The Purdue Pegboard test was conducted to assess hand functions. The score of the dominant hand of subjects before participating in horticultural activities was $14.2(\mathrm{SD}=3.7)$, and the score after participating in planting, wrapping pots, making mini flower baskets, wrapping a single flower and making corsages was $14.4(\mathrm{SD}=3.7), 14.7(\mathrm{SD}=4.2)$, $15.0(\mathrm{SD}=3.0), 14.5(\mathrm{SD}=3.9)$, and $14.9(\mathrm{SD}=3.6)$ respectively, maintaining the average level of people with mental disabilities. There was no significant difference between programs $(p=.639)$. The score of the non-domi- 
nant hand of subjects before participating in horticultural activities was $12.8(\mathrm{SD}=2.8)$, and the score after participating in planting, wrapping pots, making mini flower baskets, wrapping a single flower and making corsages was $12.6(\mathrm{SD}=2.4), 13.0(\mathrm{SD}=3.1), 14.0(\mathrm{SD}=3.2), 13.4$ $(\mathrm{SD}=4.3)$, and $13.5(\mathrm{SD}=2.9)$ respectively, maintaining the average level of people with mental disabilities. There was no significant difference between programs $(p=.248)$. The score of the both hands of subjects before participating in horticultural activities was $10.5(\mathrm{SD}=2.8)$, and the score after participating in planting, wrapping pots, making mini flower baskets, wrapping a single flower and making corsages was $10.5(\mathrm{SD}=2.6), 10.6(\mathrm{SD}=2.4), 10.5(\mathrm{SD}=2.0)$, $10.3(\mathrm{SD}=2.7)$, and $10.9(\mathrm{SD}=2.4)$ respectively, maintaining the average level of people with mental disabilities. There was no significant difference between programs ( $p=.856)$. The score of the assembly of subjects before participating in horticultural activities was $23.6 \pm 10.5$, and the score after participating in planting, wrapping pots, making mini flower baskets, wrapping a single flower and making corsages was 26.6 ( $\mathrm{SD}=11.5), 27.7(\mathrm{SD}=12.2)$, $28.0(\mathrm{SD}=13.9), 26.9(\mathrm{SD}=12.0)$, and $29.1(\mathrm{SD}=11.9)$ respectively. The score before participation was the average level of people with mental disabilities and the score increased above the average level, and there were significant differences between programs $(p=.016$; Table 2).

No significant effect was observed in the results of the dominant and non-dominant hand and both hands of subjects, but the results of assembly showed significant differences in hand functions. These results were similar to those of earlier studies. Chang et al. (2005) reported that occupational therapy activity programs to improve hand functions improved not only the hand functions of those with intellectual disabilities but also their ability to perform tasks that required hand functions. Lee and Kim (2010) provided horticultural therapy programs for those with intellectual disabilities, and reported that the power of fingertips, the grip strength of hands, and the power of wrists increased after participating in a topiary program, that the power of fingertips significantly increased after participating in a pressed flower program that used hands or tweezers to pick up materials. The grip strength of hands also increased after participating in a flower decoration program that frequently used scissors, and the power of wrists was strengthened after participating in a planting program in the study. As hands are used as a tool to perform various activities and tasks in daily life, and play an important role in performing tasks also in workplaces, the number of those who need activities to improve hand functions among special-education school students continues to increase (Chang et al., 2005). These results indicate that horticultural activities can improve the hand functions and work performance of people with mental disabilities, help them fully perform their role and thus contribute to their adaptation to workplaces.

\section{Changes in working speed and observation of individuals}

The time spent to produce 10 pieces of the same product was measured, and that spent for the activity of planting decreased from $9.9(\mathrm{SD}=4.0)$ minutes in the first class to $6.0(\mathrm{SD}=2.3)$ minutes in the second class $(p=.018)$. The time spent for the activity of making mini flower baskets decreased from $35.2(\mathrm{SD}=10.1)$ minutes in the first class

Table 2. Changes in hand functions of people with mental disabilities before and after each horticultural activity program

\begin{tabular}{cccccccc}
\hline \multirow{2}{*}{ Item } & & \multicolumn{5}{c}{ After-HA } \\
\cline { 3 - 6 } & Before-HA & Planting & Wrapping pots & $\begin{array}{c}\text { Making mini } \\
\text { flower baskets }\end{array}$ & $\begin{array}{c}\text { Wrapping a } \\
\text { single flower }\end{array}$ & $\begin{array}{c}\text { Making } \\
\text { corsages }\end{array}$ & $p$ \\
\hline Dominant hand & $14.2(3.7)$ & $14.4(3.7)$ & $14.7(4.2)$ & $15.0(3.0)$ & $14.5(3.9)$ & $14.9(3.6)$ & .639 \\
Non-dominant hand & $12.8(2.8)$ & $12.6(2.4)$ & $13.0(3.1)$ & $14.0(3.2)$ & $13.4(4.3)$ & $13.5(2.9)$ & .248 \\
Both hands & $10.5(2.8)$ & $10.5(2.6)$ & $10.6(2.4)$ & $10.5(2.0)$ & $10.3(2.7)$ & $10.9(2.4)$ & .856 \\
Assembly & $23.6(10.5)$ & $26.6(11.5$ & $27.7(12.2)$ & $28.0(13.9)$ & $26.9(12.0)$ & $29.1(11.9)$ & $.016^{*}$ \\
\hline
\end{tabular}

Note. Standard deviations appear in parentheses next to means. HA $=$ horticultural activities.

${ }^{*} p<.05$ by Friedman test. 
to $21.0(\mathrm{SD}=7.7)$ minutes in the second class $(p=.018)$, and that spent for the activity of wrapping a single flower decreased from $23.3(\mathrm{SD}=7.9)$ minutes in the first class to $16.2(\mathrm{SD}=7.3)$ minutes in the second class $(p=.043)$. The time spent for the activity of making corsages also decreased from $53.6(\mathrm{SD}=15.9)$ in the first class to 40.8 $(\mathrm{SD}=16.8)$ minutes in the second class $(p=.043)$. These results showed that the time spent for the second class significantly decreased from the time spent in the first class. The time spent for the activity of wrapping pots slightly decreased from $52.7(\mathrm{SD}=11.7)$ minutes in the first class to $49.6(\mathrm{SD}=17.8)$ minutes in the second class, but there was no significant difference $(p=.398$; Table 3$)$.

Subject A wrapped flowers off the center of a wrapping paper at first, but after repeating the activity several times the subject wrapped flowers well checking the center. In the first class of making mini flower baskets, Subject A tended to make baskets with flowers at the same height, but in the second class the subject arranged flowers at different heights. In the first class of making corsages, Subject A thought over various ways to do it easily and tried various ways and in the second class they seemed to enjoy the task humming a song.

Subject B similar to Subject A also could not wrap flowers well at first, but successfully found the center of a wrapping paper after repeating it.

Subject $\mathrm{C}$ seemed to feel uncomfortable and stressed wrapping pots and wrapping a single flower and to feel unconfident about outcomes at first, but said the outcomes were beautiful and resolved to make them better later at the end of the first class, showing satisfaction with them. In addition, Subject $\mathrm{C}$ seemed to feel uncomfortable waterproofing pots even in the second class, and thus an instructor told the subject how to do one more time. After that, Subject $\mathrm{C}$ successfully completed the task without any help, showing a more smooth process and better outcomes. In the first class of making mini flower baskets, leaves on stem were not cleanly removed, or flowers tended to be put too deeply, with some stems penetrating through a floral foam. However, in the second class, some improvements were observed. In particular, when being praised, Subject C looked very grateful and happy.

Subject D planted 10 pieces one after another in the first class of planting, but in the second class the subject divided the task into several steps, and performed the task more efficiently by completing one step for 10 pieces at once and doing the next step. Subject D seemed to be unskilled at making mini flower baskets at first, but to be strongly determined to do it alone, and thus listened carefully to instructions and asked questions as soon as any problems or questions about horticulture came up. In addition, in the second class, Subject D checked necessary materials voluntarily.

Subject E seemed to feel tired after wrapping three pots,

Table 3. Differences in work speed (unit: minutes) of people with mental disabilities between the first and second class of each horticultural activity program

\begin{tabular}{cccc}
\hline Session & Program & Work speed & $p$ \\
\hline 1 & Planting & $9.9(4.0)$ & $.018^{*}$ \\
2 & Wrapping pots & $6.0(2.3)$ & .398 \\
3 & & $52.7(11.7)$ & \\
4 & Making mini flower baskets & $49.6(17.8)$ & $.018^{*}$ \\
\hline 5 & & $35.2(10.1)$ & $.043^{*}$ \\
6 & Wrapping a single flower & $21.0(7.7)$ & $.043^{*}$ \\
\hline 7 & & $23.3(7.9)$ & $16.2(7.3)$ \\
\hline
\end{tabular}

Note. Standard deviations appear in parentheses next to means.

${ }^{*} p<.05$ by Wilcoxon signed rank test. 
and took a break after completing one repeatedly, showing a slow working speed in the first class. In the second class, for the first three pots, the subject seemed to be confused about the process of wrapping pots, but wrapped the rest pots alone without taking a break. In the first class of wrapping a single flower, flowers were wrapped loosely, but in the second class Subject E could fix flowers firmly. Making corsages seemed to be difficult, but Subject E said it was fun and showed a higher concentration and interest compared to other classes. After completing the program, the subject said it was fun to do manual tasks.

Subject F similar to Subject D planted 10 pieces one after another in the first class, but in the second class Subject $\mathrm{F}$ divided the task into several steps, and performed the task more efficiently by completing one step for 10 pieces at once and doing the next step. The subject hurriedly finished the activity of wrapping pots at first, but started to wrap them slowly from the 5th pot in the first class. After completing 10 pieces, Subject $\mathrm{F}$ even compared the first one with the last one. In the second class, the subject cleaned the desk while doing the task. In the class of making mini flower baskets, Subject F showed a higher concentration and interest, and came forward to see the demonstration of the instructor more closely, and said that Subject $\mathrm{F}$ found oneself passive, but became more active as classes were repeated.

In the class of making mini flower baskets and wrapping a single flower, Subject G started to help distribute materials before the classes and help others complete the task before the class was completed. In the class of wrapping a single flower, after finishing the task early, Subject $G$ helped others who were struggling and took photos of the products the subject made, being pleased with them. Subject $\mathrm{G}$ seemed to be very shy at first, but started to talk more and look happy as classes were repeated.

As subjects repeated tasks, they started to identify problems on their own and tried new ways to address them and reduce their working speed, gradually increasing the completeness of their products. Repeating tasks improved their understanding of tasks and skills, which demonstrated that it was effective in acquiring skills rapidly and precisely. In addition, the passive attitudes of subjects in the early stage were gradually replaced by pleasant, active and friend- ly images.

There are many types of disorders and the ability to work and adaptability vary significantly. Those with disabilities and their parents said that only very few training programs customized for each type of disorders were available and that efficient training programs needed to be provided considering their characteristics (Lee, 2012). As a series of crimes committed by those with schizophrenia have been reported recently, schizophrenia, a type of mental disorder, has was put on the list of search keywords on the Internet for a while as a social issue. The people with mental disabilities are usually like normal people but it is still difficult to completely guarantee their safety. Even those who received training are not trained for other elements apart from work-related skills. For this reason employers themselves may not make decisions easily and for this reason people with mental disabilities may not find a job even after diligently participating in vocational rehabilitation training (Lee, 2012). In addition, the economically inactive population of those with disabilities were surveyed on their subjectively assessed possibility of employment, and the majority of those who intended to work answered that they could 'work for a short time or do a simple work (50.2\%)' (Korea Employment Agency for Persons with Disabilities, 2018). Therefore, considering the characteristics of people with mental disabilities, workplaces that do not require staying at work for a long time or additional training for adaptation to the working environment but require working skills only like part-time works or working from home are recommended to reduce burden both on employers and employees. Providing training that applies repetitive tasks for people with mental disabilities to learn work skills intensively considering their characteristics is expected to be effective when providing vocational rehabilitation for them.

\section{Conclusion}

This study was conducted to identify training methods for developing vocational rehabilitation programs suitable for people with mental disabilities. The results of this study first showed that the process of repeatedly making horticultural products improved the hand functions of people with 
mental disabilities. Hands are tools to perform various activities and tasks in daily life, and play an important role in performing tasks also in workplaces. Therefore, horticultural activities are expected to improve the hand functions of people with mental disabilities and their ability to work, and to help them fully perform their role for their better adaptation to workplaces. Second, the time spent to produce 10 pieces of the same product was measured, and the time spent to do in the second class was shorter than that in the first class. Subjects identified problems and tried new ways to increase efficiency in the process of repeating tasks. In addition, the completeness of products gradually improved. Based on the results, it can be concluded that repetitive tasks are an effective training method to improve the understanding of tasks and skills and acquire skills rapidly and accurately. The passive attitudes of subjects in the early stage were gradually replaced by pleasant, active and friendly images. Lee (2012) pointed out that there are many types of disorders and the ability to work and adaptability vary significantly. Those with disabilities and their parents said that it is necessary to provide training programs customized for each type of disorders. Workplaces that do not require staying at work for a long time and additional training for adaptation to the working environment but require working skills only are recommended for people with mental disabilities, and considering these characteristics, training methods that apply repetitive tasks for intensively learning skills seem to be effective.

As subjects in this study were selected from one institution located in a certain area, the number of samples was very low, and thus they were recognized as one experimental group without distinguishing seven subjects whose gender, age and level of disorders were all different. Kim et al. (2005) was also conducted on a limited number of subjects considering that one-on-one activities with a therapist can maximize therapeutic effects for people with intellectual disabilities. Considering the characteristics of this study, it is difficult to generalize the results of this study, but the effectiveness of this can be verified and supplemented by conducting a follow-up study on a larger number of samples. It is also expected to develop horticultural activity programs for vocational rehabilitation that can encourage people with mental disabilities to participate in occupational training without burden and to engage in economic activities.

\section{References}

Chang, K.Y., W.H. Kim, and C.W. Han. 2005. The effects of occupational activity program for hand function and occupational performance ability on mentally retarded adults. J. Voc. Rehabil. 15(2):213-233.

Choi, S.H. 2015. A study on the determinants of the job satisfaction of the employed people with mental illness. Master's thesis, Nambu University, Gwangju, Korea.

Jeuong, S.W., Y.J. Kang, and S.H. Lee. 2019. A study on the roles and program areas of vocational adjustment training facilities for the disabled. Health Welf. 21(1):149-176. https://doi.org/10.23948/kshw.2019.03.21.1.149

Kang, Y.J. 2004. PurduePegboard standardization for vocational evaluation of the disabled: Implementation and interpretation. Disabil. Employ. 14(4):85-96.

Kim, J.H. 2012. Effect of horticultural occupational therapy utilizing a floral arrangement on vocational-achievement ability of chronic schizophrenia patients. Master's thesis, University of Seoul, Seoul, Korea.

Kim, M.S., J.O. Houng, and S.H. Chung. 2005. Effects of horticultural therapy program on the dexterity and adaptive behavior of the mentally retarded juvenile for vocational rehabilitation. J. Korean Soc. People Plants Environ. 8(4):99-105.

Korea Employment Agency for the Persons with Disabilities. 1995. A study on the post occupational disability guidelines. Gyeonggi-do, Korea: Author.

Korea Employment Agency for the Persons with Disabilities. 2018. The statistics of persons with disabilities for 2018 . Gyeonggi-do, Korea: Author.

Lee, E.M. 2012. A study on needs and conditions of vocational rehabilitation experienced by the people with disability and their parents. Disabil. Employ. 22(4):295-322. https://doi.org/10.15707/disem.2012.22.4.012

Lee, H.K., H.C. Chong, and E.W. Lee. 2014. Factors associated with income of workers with mental disability: Using the Korean panel survey of employment for the disabled. Health Serv. Manag. Rev. 8(2):1-7. https://do- 
i.org/10.18014/hsmr.2014.8.2.1

Lee, M.J. and H.Y. Kim. 2010. Effect of horticultural therapy program applying prompt on the hand function of the intellectual disabilities. Korean J. Hortic. Sci. Technol. 28(1):132-137.

Lee, M.J. and W. Oh. 2012. Effect of making topiary though analysis of horticultural activity on vocational skill and adaptive behavior of intellectually challenged people. J. Korean Soc. People Plants Environ. 15(5):349-355.

Mun, S.Y. 2011. A qualitative case study of mentally handicapped vocational rehabilitation service : Based on mobile steam car wash business. Korean J. Local Gov. Adm. Stud. 25(2):299-317. https://doi.org/10.18398/kjlg as.2011.25.2.299
Na, W.H. 2011. An analysis of research subject and trend on vocational rehabilitation for persons with disabilities. J. Spec. Educ. Rehabil. Sci. 50(1):35-53.

Park, H.M., G.S. Kim, O.S. Lee, and C.E. Song. 2010. Effect of horticultural therapy program on the vocational rehabilitation in a mentally retarded person. Proceedings of Spring Conference of Korean Institute of Forest Recreation and Welfare (pp. 149-150).

Seol, G.A., S.Y. Yun, and B.J. Choi. 2019. The effects of making horticultural products and selling activities on vocational rehabilitation of persons with mental disabilities. J. People Plants Environ. 22(3):279-287. https://doi.org/10.11628/ksppe.2019.22.3.279 